\title{
PROTOTIPE RANCANG BANGUN PINTU BENDUNGAN OTOMATIS UNTUK IRIGASI PERTANIAN BERBASIS MIKROKONTROLER ARDUINO ATMEGA328
}

\author{
Iman Permana ${ }^{1)}$ \\ ${ }^{1}$ Fakultas Sains dan Teknologi, Universitas Muhammadiyah Sukabumi \\ email: imanummi17@gmail.com
}

\begin{abstract}
Technology as a result of human inventions to facilitate the work of increasingly advanced human technology and the development of various kinds of innovations especially developments in the field of microcontroller technological inventions penetrated various aspects ranging from transportation medicine and agriculture The large number of residents who use hydropower dams as water storage Open and close water dam gates automatically are buildings and structures that can function to open and close the flow of water to the river upstream according to the water level at the headwaters or dams. This tool uses the principle water level control work for water level detection using ultrasonic sensors with the design of this tool can then make it easier in terms of monitoing in opening and opening the water dam door automatically so as to facilitate in regulating the flow of water discharge without having to use a guard by adding an LCD to make it easier to show water level information and alarms on dams that can change in an uncertain period of time and then discharge reportsthe height of the water can be seen through the web so that it can facilitate and reduce a human error factor human error
\end{abstract}

Keywords: Dam, Automatic, Microcontroller. Human error, Ultrasonic, Water level control,

Abstrak

Teknologi sebagai hasil penemuan ciptaan manusia untuk mempermudah pekerjaan manusia teknologi yang semakin maju dan berkembangannya berbagai macam inovasi terutama perkembangan dibidang Mikrokontroler penemuan teknologi merambah berbagai aspek mulai dari transportasi,kedokteran dan pertaniaan Banyaknya penduduk yang memamfaatkan bendungan PLTA sebagai tempat penyimpanan air Buka dan tutup pintu bendungan air secara otomatis merupakan bangunan dan stuktur yang dapat berfungsi untuk membuka dan menutup aliran air ke hulu sungai sesuai dengan ketinggian air pada hulu sungai atau bendungan Alat ini menggunakan prinsip kerja water level control untuk pendeteksi ketinggian air menggunakan sensor ultrasonic dengan dirancangnya alat ini kemudian dapat memudahkan dalam hal monitoing dalam buka dant utupan pintu bendungan air secara otomatis seingga memudahkan dalam hal mengatur aliran debit air tanpa harus mengunakan seorang penjaga dengan menambahkan lcd untuk memudahkan dalam menunjukkan informasi dan alarm ketingan air pada bendungan yang bisa berubah dalam kurun waktu yang tidak menentu dan kemudian laporan debit ketinggian air pun bisa dilihat melalui web sehingga bisa memudahkan dan mengurangi sebuah faktor kelalaian manusia human error.

Keywords: Bendungan,Otomatis,Mikrokontroler.Human error, Ultrasonic, Water level control,

\section{PENDAHULUAN}

Teknologi sebagai hasil penemuan ciptaan manusia untuk mempermudah pekerjaan manusia teknologi yang semakin maju dapat mempermudah manusia dalam memenuhi kebutuhan hidupnya di zaman modern seperti sekarang ini berbagai macam inovasi penemuan teknologi merambah dalam aspek kebutuhan manusia mulai dari transportasi, telekomunikasi, kedokteran, dsn pertanian, sampai dunia industri yang semakin canggih dan berkembang, [1]. Banyak masyrakat yang memanfaatkan bendungan untuk PLTA sebagai penyimpanan air, pertanian, mencegah banjir dan lain-lain bendungan menjadi suatu alternatif yang bisa digunakan oleh masyarakat [2]. Setiap bendungan selalu terdapat pintu bendungan irigasi air yang harus dibuka dan ditutup sesuai dengan debit air yang dibutuhkan 
sehingga dapat digunakan sesuai dengan kebutuhannya pengunaan pintu bendungan ini sudah ada sejak dari zaman dahulu sampai dengan zaman modern sekarabg ini sehingga sangat bermanfaat dalam hal ini bendungan sudah menjadi alternative [3] Pintu bendungan air secara pengoperasianya diantaranya yaitu secara manual dan secara semi otomatis pengunaan dalam hal manual sering kita lihat pada irigasi pesawahan yang aliran air bertekanan rendah sedangkan untuk aliran air yang bertekanan tinggi sering kita jumpai pada bendungan danau dan untuk full otomatis digunakan dalam pengaturan untuk pengendalian banjir [4]. Buka dan tutup pintu bendungan air secara otomatis merupakan bangunan dan stuktur instalasinya yang dapat berfungsi untuk membuka dan menutup aliran debit air ke bendungan atau waduk [5]. Kebanyakan bendungan memiliki sebuah bagian yang disebut dengan pintu air yang terletak di hulu sungai atau ujung bendungan yang berperan untuk menampung dan membuang air yang berlebihan secara bertahap dan terus menerus sesuai dengan volume air yang tidak stabil pada bendungan sebaiknya jika jumlah air berubah dalam priode waktu yang tidak menentu sistem kontrol pengendalian pintu bendungan air pada sungai atau waduk bisa secara otomatis tertutup dan terbuka karena perubahan debit air yang selalu tidak menentu dalam kurun waktu tidak bisa ditentukan [6].

Kebanyakan bendungan memiliki sebuah bagian yang disebut dengan pintu air yang terletak di hulu sungai atau ujung bendungan yang berperan untuk menampung dan membuang air yang berlebihan secara bertahap dan terus menerus sesuai dengan volume air yang tidak stabil [7]. Untuk mengatasi masalah tersebut diperlukan adanya suatu alat kontrol pengendali pintu bendungan yang dapat memantau monitoring dalam hal ketinggian debit air dan sekaligus dapat membuka kemudian menutup pintu bendungan air secara bersamaan selain itu dapat mengetahui laporan ketinggian debit air yang dapat berubah dalam priode waktu yang tidak dapat menentu dengan merangcang sistem alat yang otomatis maka faktor kelalaian yang sering terjadi pada manusia dapat segera dihindari sehingga penjagaan pintu air dapat terkendali sehingga tidak mengakibatkan volume air yang tidak stabil sehingga mengakibatkan sering terjadi kelalaian dalam hal penjagaan sehingga mengakibatkan terjadinya kerusakan pada lingkungan akibat dari kelalaian tersebut maka dari itu dengan dirancangnya sebuah alat prototipe ini dapat memonotoring pengendalian volume debit air akan semakin mudah dan stabil sehingga dapat membantu pengoperasian pembukaan dan penutupan pintu bendungan secara otomatis berbasis mikrokontroler arduino [8]

\section{METODE PENELITIAN}

Dalam penelitian ini yaitu menggunakan metode Prototipe (Prototyping) pototipe adalah pemodelan evolusioner yang bersifat iterative yang meliputi sebuah model proses perangkat keras terdiri dari perancangan perangkat keras dan perancangan perangkat lunak shingga menjadi sebuah alat yang bisa menjadi solusi ada beberapa tahap dan langkah-langkah dilakukan mulai dari proses perancangan elektronika perangkat keras dan perancangan sistem perangkat lunak yang bertujuan untuk mendapatkan hasil sehingga tujuan dari penelitian tersebut dapat terpenuhi metodologi penelitian yang digunakan untuk membuat prototipe rancang bangun pintu bendungan irigasi air otomatis berbasis mikrokontroler Arduino ATMEGA328.

\section{- Analisis Kebutuhan Sistem}

Analisis kebutuhan sistem meliputi diantaranya yaitu tahap dimana peneliti menentukan kebutuhan untuk pembuatan alat dari mulai sebuah rancangan alat analisis kebutuhan sistem guna untuk memenuhi tujuan tersebut peneliti menggunakan sistem input dan output dalam pembuatan alat prototipe ini sehingga alat ini dapat digunakan dengan proses yang sudah di tentukan.

\section{- Tahap Perancangan}

Dalam Tahap Perancangan penelitian ini merupakan suatu rencana yang komprehensif dan memiliki tujuan yang terarah dalam melakukan penelitian untuk menghasilkan karya sesuai dengan yang diinginkan hal yang dilakukan dalam perancangan prototipe rancang bangun pintu bendungan irigasi air otomatis berbasis mikrokontroler menggunakan water level sensor ini terdiri dari beberapa tahapan diantranya:

\section{Perancangan Kebutuhan Sistem}


Analisis kebutuhan sistem adalah tahap dimana peneliti menentukan kebutuhan dari sistem agar prototipe rancang bangun pintu bendungan irigasi air otomatis berbasis mikrokontroler ini dapat digunakan sesuai dengan tujuan penelitian

2. Perencangan Perangkat Lunak

Perancangan perangkat lunak berupa perancangan program yang dibuat untuk mendukung sistem kerja dari prototipe pintu air otomatis yang dapat dihubungkan dengan software IDE Arduino untuk mendapatkan sistem yang baik

3. Perancangan Perangkat Keras

Dalam tahap ini perancangan Hadware sangat menentukan keberhasilan suatu alat yang akan dibuat didalam perancangan hadware prototipe rancang bangun pintu bendungan air otomatis ini harus dirancang sedemikian kuat dan stabil

4. Pembuatan Alat

Pada tahap pembuatan yaitu mulai membuat alat sesuai dengan tahap perancangan sebelumnya proses pembuatan alat mengunakan Arduino dengan bahasa pemprograman $\mathrm{C}$

5. Pengujian Alat

Tahapan pengujian ini dilakukan setelah semua proses di atas telah selesai termasuk proses pembuatan kemudian pengujian alat akan alat yang sudah dirancang.

\section{- Perancangan Hadware}

Dalam perancangan elektronika alat untuk membangun pintu irigasi bendungan otomastis ada beberapa yang perangkat yang harus dirancang yaitu :

1. Perancangan Mikrokontroller Arduino ATmega328

2. Perancangan Sensor Ultrasonic HC-SR04

3. Perancangan LCD

4. Perancangan Buzzer

5. Perancangan Perangan Relay

- Teknik Pengumpulan Data

1. Observasi

Observasi dilakukan untuk mengumpulkan data yang jelas yang akan di singkron kan dengan penelitian dalam mencari data tersebut peneliti memakai metode observasi dalam menganalisa dan mencari sebuah objek untuk sebuah penelitian guna mendapatkan data yang pasti secara fakta agar bisa melakukan penelitian

2. Studi Pustaka
Studi pustaka dilakukan menggunakan mencari teori-teori apa yang akan digunakan dalam merampungkan sumber informasi yang akan diteliti, dan menerima dasar-dasar referensi yang jelas sesuai fakta dan data bagi peneliti untuk evaluasi yg didapat dari ebook jurnal ilmiah dan web internet

\section{- Studi Pustaka Prototipe}

Prototipe untuk pengembang sistem yang bertujuan untunkn mengumpulkan informasi dari penguna sehingga pengguna dapat berinteraksi dengan model prototipe yang dikembangkan karena prototipe menggambarkan versi awal sistem dan digunakan untuk melanjutkan sistem dan digunakan untuk melanjutkan sistem actual yang lebih besar.

\section{Bendungan}

Bendungan adalah stuktur yang dibangun untuk menahan akiran air dan dapat digunakan sebagai reservoir, danau, atau tempat resrease kebanyakan dam pula memiliki bagian yang dianggap pinu air utuk membuang air yang tidak diinginkan secara bertahap atau berkelanjutan.

\section{Mikrokontroler}

Mikrokontroler sering digunakan pada sistem yang tidak terlalu kompleks. Sistem yang menggunakan mikrokontroler sering disebutsebagai embedded system atau dedicated system. Embeded system adalah sistem pengendali yang tertanam pada suatu produk, sedangkan dedicated system adalah sistem pengendali yang dimaksudkanhanya untuk suatu fungsi tertentu. mikrokontroler sebagai pengendali dan juga dedicated system karena fungsi pengendali tersebut berfungsi hanya untuk menerima data.

\section{Arduino}

Arduino bisa dikatakan sebagai sebuah Flatform dari Physical Computing yang bersifat terbuka untuk Flatfrom disini adalah sebuah pilihan kata yang tepat Arduino tidak hanya sekedar sebuah alat pengembangan kombinasi dari hadware dalam bahasa pemerograman dan intergrated development environment (IDE) yang canggih IDE adalah sebuag Sofware yang sangat berperan untuk menulis program menjadi kode biner dan di upload ke dalam chip mikrokontroler. 


\section{HASIL DAN PEMBAHASAN}

\section{- Analisis dan Perancangan}

Perancangan merupakan suatu tahap yang paling penting baik perancangan mekanik maupun perancangan elektroniknya tahap dalam perancangan alat ini diantaranya adalah pemilihan komponen yang mempunyai karakteristik sesuai dengan kebutuhan untuk itu dibutuhkan buku petunjuk yang memuat spesifikasi komponen dan kemudian dilanjutkan dengan melakukan percobaan dan pengujian maupun pengukuran komponenkomponen tersebut setelah komponen yang memenuhi syarat didapatkan maka tahap selanjutnya adalah pembuatan alat tersebut bagian dari perancangan ini ditunjukkan untuk memenuhi kerja sistem alat yang akan di rancang dan dibuat mengingat pentingnya tahap perancangan dan pembuatan maka perlu dilakukan dengan tepat sesuai dengan rangakian

\section{- Fungsi dan Cara Kerja Alat}

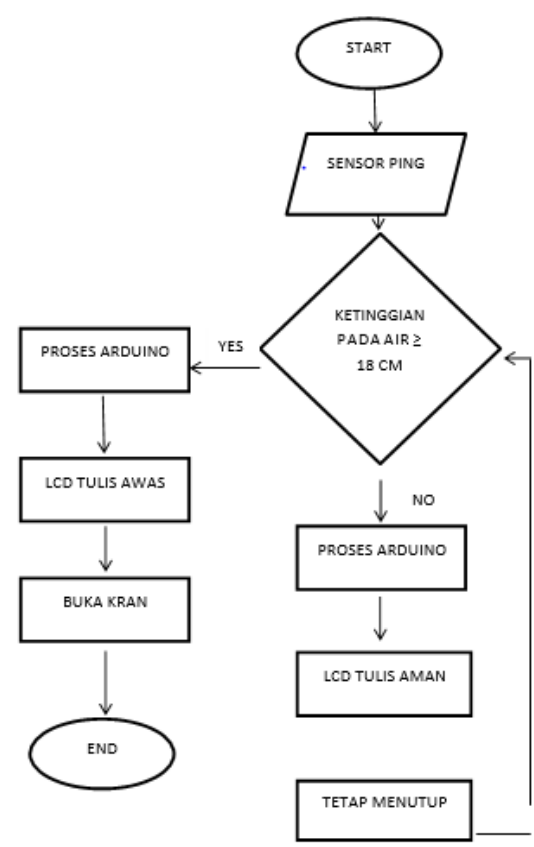

Gambar.1. Flowchart Pintu Bendungan Otomatis

Flowcahart alur pintu bendungan otomatis fungsi dari alat sistem bendungan otomatis ini adalah untuk memantau ketinggian debit air yang tidak menentu dalam suatu bendungan. Cara Kerja dari sistem alat ini adalah jika sensor PING membaca level ketinggian air, maka LCD akan terus menampilkan level dari ketinggian air tersebut, apabila level air sudah mendekati $25 \mathrm{~cm}$ maka rangkaian buzzer akan berbunyi dalam bentuk suara, sedangkan LCD menampilkan output ketinggian air yang dipantau oleh sensor PING, kemudian keran akan menyala hingga level ketinggian air mencapai $10 \mathrm{~cm}$, sedangkan apabila level air sudah berada pada $10 \mathrm{~cm}$ maka akan kembali bekerja pompa air

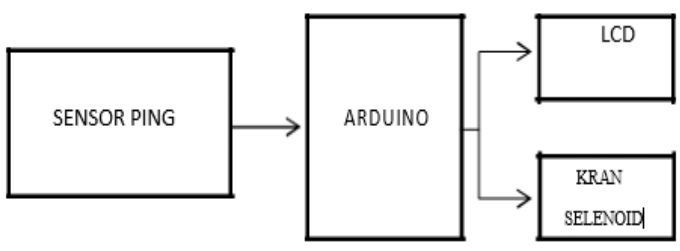

Gambar 2. Blok Diagram Sistem

Blok Diagram Sistem yang pertama dilakukan saat sistem air akan dideteksi oleh water level sensor sensor ping kemudian akan diproses oleh Arduino kemudian ketinggian air akan terdeksi oleh sensor lalu kemudian akan menampilkan laporan ke LCD lalu keran senior akan terbuka otomatis

\section{- Peracangan Alat}

Blok diagram sistem bendungan otomatis ini memiliki tiga bagian proses kerja, meliputi: input proses output

Bagian pertama input, menunjukkan bahwa mikrokontroler menerima masukan dari sensor PING dapat melakukan seleksi kondisi waspada, aman, serta darurat. Sedangkan dalam proses mikrokontroler akan secara otomatis memproses dari input sensor PING, output dari diagram blok mengeluarkan informasi yang telah diolah menjadi suatu peringatan yang akan muncul pada LCD, bila status air mencapai ketinggian maksimal buzzer akan menyala dan kran selenoid akan terbuka secara otomatis.

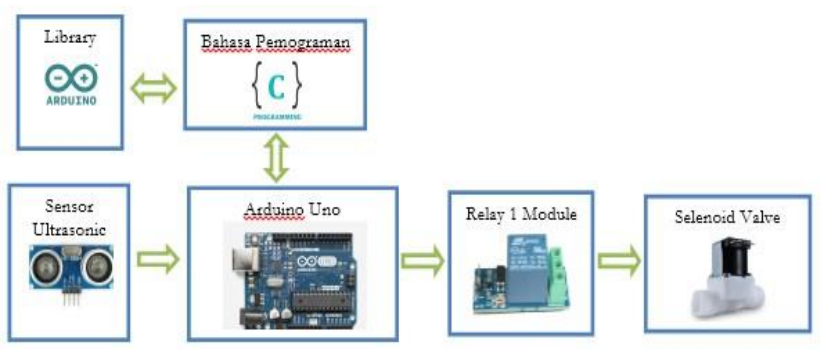

Gambar 3.Blok Diagram Rangkaian Sitem 
- Rangkaian Bendungan Otomatis

Rangkaian Arduino input proes Penerapan skema rangkaian proses dan output

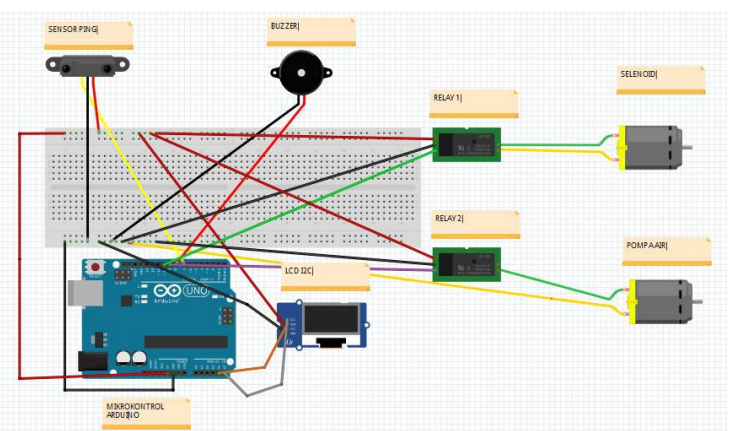

Gambar 4. Rangakaian Alat Bendungan

Dalam perancangan perancangan prototipe ini mengunakan sensor ultrasonik dan rangkaian yang tersusun melalu Arduino Uno terdapat 2 tahap dalam perancangan proses alat ini yaitu hardware dan software bagian pertama adalah input kemudian menunjukkan bahwa mikrokontroler menerima masukan dari sensor PING dapat melakukan seleksi kondisi waspada, aman, serta darurat sedangkan dalam proses mikrokontroler akan secara otomatis memproses dari input sensor PING output kemudian mengeluarkan informasi yang telah diolah menjadi suatu peringatan yang akan muncul pada LCD, apabila status air mencapai ketinggian maksimal buzzer akan menyala dan kran selenoid akan terbuka secara otomatis

\begin{tabular}{ll}
\hline Perangkat & Kegunaan \\
\hline Mikrokontroller & Pengatur \\
Arduino & \\
Sensor PING & Pengukuran \\
LCD & Menampilkan \\
Buzzer & Alarm \\
Relay & Tenaga \\
Kran Selenoid & Output \\
\hline
\end{tabular}

Tabel 1.1 Perangkat yang Digunakan

\section{SIMPULAN DAN SARAN Kesimpulan}

Sistem Bendungan Otomatis Berbasis Arduino ini, dapat memberikan peringatan baik itu dalam bentuk suara/audio dari buzzer, ataupun dalam bentuk visual dari LCD. Sehingga dapat memberi info detail level ketinggian air pada suatu bendungan. ketika ketinggian air mencapai batas maksimal maka selenoid akan terbuka seara otomatis dan akan menutup kembali apabila tahap level air sudah aman.

Saran

Adapun Saran-saran tersebut adalah Diharapkan programmer selanjutnya dapat menggembangkan alat ini dengan menggunakan program-program lainya selain Arduino Apabila digunakan pada skala sebenarnya maka selenoid dapat diganti dengan dinamo yang mengubah energi listrik menjadi energi statis yang dapa membuka pintu bendungan yang lebih besar.

\section{DAFTAR PUSTAKA}

[1] B. P. Lapanporo, Hengki, and Nurhasanah, "Prototipe Sistem Telemetri Tinggi Muka Air dan Kontrol Pintu Air Otomatis," vol. V, no. 1, pp. 37-40, 2017.

[2] D. Kurniadi and A. Mulyani, "Prototipe Perangkat Lunak Sistem Kendali Peralatan Elektronik Berbasis Komputer," J. Wawasan Ilm., vol. 7, no. 12, pp. 1-11, 2015.

[3] A. Fitriandi, E. Komalasari, H. G.-J. R. dan, and undefined 2016, "Rancang Bangun Alat Monitoring Arus dan Tegangan Berbasis Mikrokontroler dengan SMS Gateway," Academia.Edu, vol. 10, no. 2, 2016.

[4] nugroho, "Pemrograman Mikrokontroler AVR," pp. 1-39, 2013.

[5] H. Wahyono and P. Rusimamto Wanarti, "RANCANG BANGUN SISTEM KONTROL KETINGGIAN AIR BENDUNGAN MENGGUNAKAN METODE PID Hendrawan Wahyono Puput Wanarti Rusimamto Abstrak," pp. 341-348.

[6] D. Purnomo, "Model Prototyping Pada Pengembangan Sistem Informasi," $J$. Inform. Merdeka Pasuruan, vol. 2, no. 2, pp. 54-61, 2017.

[7] M. R. Alfatah, "Prototype Sistem Buka Tutup Otomatis Pada Pintu Air Bendungan Untuk Mengatur Ketinggian Air Berbasis Arduino," Univ. 
Muhammadiyah Surakarta, pp. 1-11, 2016.

[8] H. Apriyanto, "Rancang Bangun Pintu Air Otomatis Menggunakan Water Level Float Switch Berbasis Mikrokontroler," J. Sisfokom (Sistem Inf. dan Komputer), vol. 4, no. 1, p. 22, 2015, doi: 10.32736/sisfokom.v4i1.132.

[9] A. Feriska and D. Triyanto, "Rancang Bangun Penjemur dan Pengering Pakaian Otomatis Berbasis Mikrokontroler," J. Coding Sist. Komput. Untan, vol. 5, no. 2, pp. 67-76, 2017.

[10] D. Setiawan, I. Zulkarnaen, P. Studi Sistem Komputer, and S. Triguna Dharma, "Prototype Alat Pemantauan Ketinggian Air Pada Bendungan Menggunakan Sensor Ultrasonik Berbasis Arduino," J. Sains Manaj. Inform. dan Komput., vol. 17, no. 2, pp. 170-174, 2018.

[11] D. Setiawan and I. Zulkarnaen, "Prototype Alat Pemantauan Ketinggian Air Pada Bendungan MenggunakaSetiawan, D., \& Zulkarnaen, I. (2018). Prototype Alat Pemantauan Ketinggian Air Pada Bendungan Menggunakan Sensor Ultrasonik Berbasis Arduino. 17(2), 170-174.n Sensor Ultrasonik Berbasis Ar," vol. 17, no. 2, pp. 170-174, 2018.

[13] A. Kurniawan, Arduino Programming with .NET and Sketch. 2017.

[14] P. Handoko, "Sistem Kendali Perangkat Elektronika Monolitik Berbasis Arduino Uno R3," no. November, pp. 1-2, 2017.

[15] M. S. Son, "Pengembangan Mikrokontroler Sebagai Remote Control Berbasis Android," J. Tek. Inform., vol. 11, no. 1, pp. 67-74, 2018, doi: 10.15408/jti.v11i1.6293.

[16] D. Junaidi and Y. D. Prabowo, Project Sistem Kendali Elektronik. 2018. 